\title{
Retextualização do texto literário de divulgação científica A Tabela Periódica no ensino de Química1
}

\author{
Arcenira Resende Lopes Targino² \\ ORCID: 0000-0003-0588-6325 \\ Marcelo Giordan ${ }^{2}$ \\ ORCID: 0000-0002-4646-0139
}

\section{Resumo}

Diversos estudos têm sugerido que a abordagem de textos de divulgação científica e de textos literários no ensino de Ciências pode trazer importantes contribuições, pois, além de permitir reflexões acerca de valores e atitudes, também pode auxiliar na construção de conceitos, contribuindo assim para o letramento científico. Tendo em vista essa perspectiva, foi elaborada e aplicada uma sequência didática (SD) intitulada Elementos químicos na natureza e na sociedade: o desastre socioambiental do Rio Doce, a qual foi aplicada na primeira série do Ensino Médio em uma escola pública da cidade de São Paulo. Após análise e seleção de alguns textos literários de divulgação científica (TLDC), excertos de algumas obras foram abordados em diferentes atividades de ensino. Neste artigo, analisamos interações discursivas observadas em sala de aula, resultantes de abordagem de capítulos do TLDC A Tabela Periódica, de autoria de Primo Levi. Dentre os resultados de aplicação, destaca-se a forma de retextualizar trechos da obra pelos estudantes e professor, em que foram observados momentos de iniciação e avaliação da interação pelos estudantes, um padrão de interação discursivo pouco frequente em sala de aula. Além disso, durante a abordagem de capítulos do TLDC em sala de aula foi constada a finalidade pedagógica de metacognição, pois foram observadas sequências discursivas em que ocorreram reflexões no que se refere às propriedades de elementos químicos. Tais resultados sugerem potencialidades didáticas da abordagem de TLDC em sala de aula de Química.

\section{Palavras-chave}

Letramento científico - Lei periódica - Sequência didática.

\footnotetext{
1- 0 presente trabalho foi realizado com apoio da Coordenação de Aperfeiçoamento de Pessoal de Nível Superior - Brasil (CAPES) - Código de Financiamento 001 e com apoio do Conselho Nacional de Desenvolvimento Científico e Tecnológico (CNPq), processo 302834/2015-0. 2- Universidade de São Paulo, São Paulo - SP, Brasil. Contatos: arceniralopes@gmail.com; giordan@usp.br 


\section{Retextualizing the literary text of science communication The periodic table in the chemistry teaching*}

\section{Abstract}

Several studies have suggested that approaching texts of science communication and literary texts in Sciences teaching can pose a major contribution, since besides of allowing reflections on values and attitudes, it can also help to construct concepts, thus contributing to achieve scientific literacy. Having such perspective in mind, it was elaborated and applied a didactic sequence (DS) denominated Chemical Elements in nature and in the society: the socioenvironmental disaster of the Doce River, which was applied in the first grade of High School in a public school in the city of São Paulo. After analyzing and selecting some literary texts of science communication (LTSC), excerpts of some works have been addressed in different teaching activities. In this article, we analyzed discursive interactions observed in the classroom after approaching some chapters of the LTSC The Periodic Table by Primo Levi. Among the results of the application, it can be pointed out the way that both students and the teacher retextualized portions of the work, and moments of initiation and assessment of interaction by the students were observed, a not common discursive interaction pattern in the classroom. Furthermore, while addressing LTSC chapters in the classroom, it was verified the pedagogic aim of the metacognition, since it was noted discursive sequences, where it happened reflections on what is related to the properties of chemical elements. Those results suggest the didactic potentialities of the LTSC in a Chemistry classroom.

\section{Keywords}

Scientific literacy - Periodic law - Didactic sequence.

\section{Introdução}

Em sala de aula circulam diversos discursos vinculados às culturas contemporâneas, sendo que, para abordagem da cultura científica e tecnológica, a qual é constitutiva da cultura atual, os textos de divulgação científica apresentam legitimidade (GOUVÊA, 2015). Conforme os apontamentos de Grillo (2006), diferentes gêneros textuais veiculam discursos de divulgação científica, como artigo, manual, aula e outros. Dentre esses gêneros, neste artigo abordamos o gênero literário.

Para Zanetic (2006), como a ciência influencia a literatura e vice-versa, a abordagem de textos literários no ensino de Ciências pode trazer contribuições, uma vez que pode

*English version by Márcia Maluf. 
favorecer uma formação mais integral dos estudantes. Além disso, para Perissé (2003), uma obra literária, quando abordada de forma interdisciplinar, pode contribuir para o desenvolvimento do senso estético e crítico, importantes para a ampliação da leitura de mundo dos estudantes. Outros autores como Coelho e Salomão (2014); Almeida e Ricon (1993); Piassi (2015); e Groto e Martins (2015) também apresentam posicionamento semelhante. Por exemplo, Piassi (2015, p. 39) argumenta que obras literárias, incluindo aquelas que não apresentam explicitamente conteúdos de Ciências, podem trazer benefícios à educação científica por consistir em produtos culturais que, de acordo com o autor, "abre uma perspectiva diante do mundo que não se sobrepõe à racionalidade científica" e "potencializa o pensar científico", por apresentar-se como mais uma forma de refletir sobre a realidade (PIASSI, 2015, p. 39).

Além disso, consideramos que a abordagem de textos dessa natureza pode contribuir para o letramento científico, o qual habilita o indivíduo a não somente decodificar informações científicas, mas também a refletir, discutir e tomar decisões responsáveis (SANTOS, 2007), uma vez que, ao apresentar elementos científicos imersos em contextos socioculturais, são favorecidas leituras que relacionam o conhecimento científico com práticas sociais.

Contudo, é preciso ponderar que a abordagem no ensino de textos literários de divulgação científica (TLDC) não é trivial de ser realizada, principalmente quando se observa que muitos desses textos não foram estruturados para terem como esfera de circulação a sala de aula. Para Cunha e Giordan (2009), esse é um aspecto que deve ser sempre observado quando se planeja desenvolver atividades de ensino com materiais de divulgação científıca, pois ao se modificar a esfera de circulação os significados também são alterados.

Nesse sentido, quando textos dessa natureza são inseridos no contexto escolar, acreditamos que cabe ao professor realizar movimentos discursivos de adequação do discurso apresentado no material à nova esfera de circulação. Consideramos que esse processo pode ser observado nas operações de retextualização realizadas por professores e alunos em sala de aula.

De acordo com Marcuschi (2007, p. 48), a retextualização refere-se ao processo de conversão de textos que incluem a conversão da fala para escrita e vice-versa, da fala para a fala e da escrita para a escrita, no qual são empregadas operações de alta complexidade que interferem nos sentidos e códigos utilizados. Para o autor, nesse processo ocorre a produção de um novo discurso em um novo gênero, uma vez que não se trata de uma mera repetição do discurso-fonte.

Devido à retextualização consistir em operações complexas, realizadas frequentemente na vida cotidiana, por exemplo, quando uma pessoa reporta para outra o que acabou de ler em um jornal, ou quando um aluno realiza anotações escritas sobre a exposição oral do professor, esse processo não deve ser menosprezado no ensino, pois apresenta grande importância para construção de significados, uma vez que para que ocorra a retextualização pressupõe-se que exista recontextualização, recriação e reconstrução do discurso-fonte (MARCUSCHI, 2007), o que só é possivel mediante algum nível de apropriação do discurso-fonte pelo interlocutor. 
Para analisar o nível de compreensão do discurso, Marcuschi (2008) considera a compreensão como um processo, que inclui ao menos quatro aspectos: estratégico, flexível, interativo e inferencial. No que se refere ao aspecto estratégico, cabe destaque que a compreensão não é uma atividade que apresenta resultados automáticos quando se seguem regras formais e lógicas, embora existam opções para otimizar a comunicação. A respeito do aspecto flexível, Marcuschi (2008) defende que não existe uma orientação única para compreensão. Para o autor, as orientações dependem do contexto discursivo e dos interactantes. Em relação ao aspecto interativo, a ideia central é a de que a compreensão é negociada, não é unilateral e é coconstruída, o que ocorre mesmo na leitura de textos escritos. Por fım, em relação ao aspecto inferencial, a compreensão não é considerada como uma atividade de decodificação, a produção de sentido ocorre quando conhecimentos de diversas fontes, referentes ao repertório cultural do leitor, relacionamse por diversos modos de raciocínio (MARCUSCHI, 2008).

Nesse sentido, nota-se que são possiveis diversas leituras a partir de um mesmo texto. No entanto, cabe destaque que ao considerar o texto como se esse pudesse ser interpretado a partir de diversos modos de leitura, pondera-se que podem ser realizadas leituras que não são coerentes com as proposições apresentadas no texto. Para analisar esses processos, Marcuschi (2008) propõe a noção de horizontes de compreensão textual. A figura 1, a seguir, apresenta um diagrama que sintetiza essa noção.

Figura 1 - Horizontes de compreensão textual

TEXTO ORIGINAL

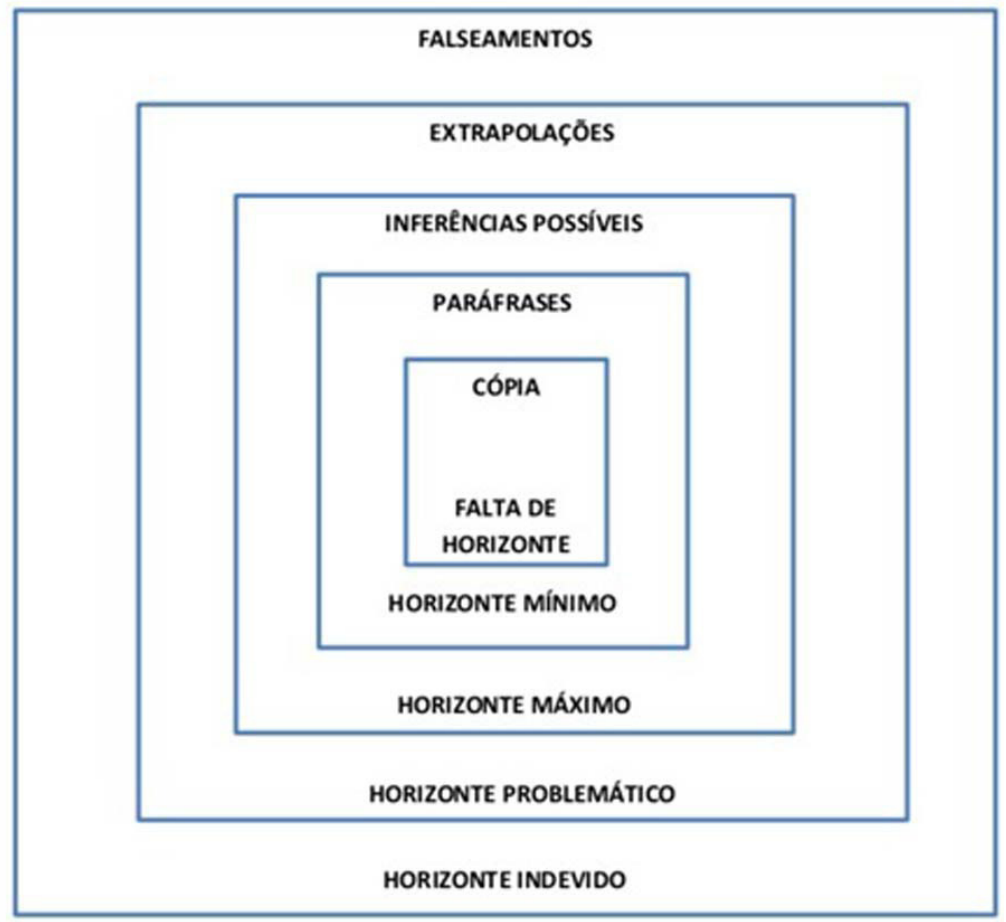


Na figura 1, são observadas cinco perspectivas ou horizontes de leitura: falta de horizonte, horizonte mínimo, horizonte máximo, horizonte problemático e horizonte indevido. 0 primeiro refere-se às repetições do texto; o segundo às paráfrases, que seria a repetição com outras palavras; o terceiro refere-se às atividades inferenciais, nas quais são relacionadas informações do próprio texto e outras do repertório cultural do leitor, e é realizada a leitura das entrelinhas do texto; o quarto trata-se de extrapolações, o qual no âmbito escolar refere-se à esfera de opinião pessoal, que, de acordo com Marcuschi (2008, p. 259), vai além das informações presentes no próprio texto e "se situa no limite da interpretabilidade”. Por fim, o quinto horizonte trata de leituras incoerentes com o sentido do texto (MARCUSCHI, 2008).

No âmbito do Ensino de Ciências, um estudo realizado por Almeida e Giordan (2014) analisou retextualizações produzidas no ensino formal. Os autores analisaram esse processo produzido por crianças após a leitura de um artigo da revista Ciência Hoje das Crianças (CHC) e constataram que no processo de retextualização as atividades de dizer o texto realizadas pelas crianças caracterizam-se como um exercício de metalinguagem, o que contribui significativamente para o letramento científico das crianças.

Cabe ressaltar que é de grande valia considerar as interações em sala de aula, pois essas, especialmente as discursivas, estão imbricadas no processo de construção de significados, de modo que a análise dessas interações é importante para entender como os significados são construídos em sala de aula (MORTIMER; SCOTT, 2002). Nesse sentido, Cunha e Giordan (2012) argumentam que essas interações, que também são culturais, são primordiais no processo de construção de significados, uma vez que é por meio delas que os indivíduos reinterpretam e criam significados para informações e conceitos.

Considerando essa perspectiva, neste trabalho apresentamos análises e reflexões de operações de retextualizações de trechos da obra A Tabela Periódica, de autoria de Primo Levi, realizadas por professores e alunos, no âmbito de aulas de Química no Ensino Médio. Desta forma, na próxima seção trataremos dos detalhes da metodologia que adotamos para estruturação das atividades de ensino com a obra e para análise dos resultados obtidos.

\section{Metodologia}

Para abordar em sala de aula trechos da obra A Tabela Periódica, de autoria de Primo Levi, no âmbito de uma pesquisa de mestrado, elaboramos uma sequência didática (SD) de duração de doze aulas intitulada Elementos químicos na natureza e na sociedade: o desastre socioambiental do Rio Doce. Cabe destaque à opção de inserir atividades sobre o TLDC em uma SD se deve ao fato de que consideramos que era preciso criar um contexto para que a abordagem da obra dialogasse com outros propósitos de ensino previstos no currículo de Química.

A SD foi elaborada conforme as diretrizes do Modelo Topológico de Ensino (MTE) (GIORDAN, 2008), o qual prevê variações nas abordagens comunicativas e nos suportes de ensino. Sendo assim, além do texto literário de divulgação científica (TLDC) A Tabela Periódica, também foram abordados trechos de outros dois TLDC, além de terem sido utilizados vídeos de reportagens jornalísticas, cartões de elementos químicos, gráficos para representar propriedades periódicas, experimentos e outros suportes. 
Para as atividades envolvendo os TLDC foi adotado um nível crescente de complexidade da atividade e também da linguagem adotada na obra. Sendo assim, a atividade com o TLDC $A$ Tabela Periódica foi aplicada ao final da SD, por consistir no TLDC de maior complexidade na linguagem e apresentar um estilo notavelmente mais literário que os demais, além de um contexto narrativo mais complexo. Além disso, a atividade realizada foi a que exigia maior autonomia dos alunos, apresentação de seminários com base em resenhas previamente elaboradas sobre trechos da obra.

Dentre os dezoito capítulos que compõem o TLDC A Tabela Periódica foram escolhidos cinco para serem abordados na SD, os capítulos Ferro, Niquel, Ouro, Mercúrio e Chumbo. Eles foram selecionados por relacionarem-se com o tema central da SD, mineração. Desses capítulos, os três primeiros são autobiográficos e os demais são ficcionais.

A SD elaborada foi aplicada durante o primeiro semestre de 2016 em uma escola pública da rede municipal de ensino na cidade de São Paulo. Todas as aulas da SD foram gravadas em áudio e em vídeo. Para a gravação das aulas seguimos a metodologia proposta por Giordan (2008). Para isso, foram utilizadas duas câmeras para captação dos registros audiovisuais e microfones sem fıo para captação do áudio. Uma das câmeras foi fixada no fundo da sala de aula e outra na lateral, a qual era movimentada conforme interesse na captação de determinadas interações em sala de aula. Um dos microfones sem fio foi fixado na lapela do professor e os demais foram distribuídos nas mesas onde os alunos sentavam-se em grupos.

Após as videogravações das aulas, elas foram assistidas diversas vezes para identificação dos temas e dos propósitos de ensino predominantes em cada parte da aula, para posterior mapeamento com a segmentação das aulas em episódios de ensino e suas respectivas sequências discursivas. Para isso, guiamo-nos nas indicações de Martins (2006), que considera que eventos indicados em um mapa são resultantes da interação do pesquisador com o material empírico, considerando o interesse e o referencial teórico adotado na pesquisa.

Utilizando esses mapeamentos, escolhemos alguns episódios de ensino envolvendo a abordagem do TLDC A Tabela Periódica em sala de aula. Para análise do episódio, com o intuito de verificar quais operações de retextualização ocorreram, transcrevemos as interações discursivas, conforme a metodologia adotada por Almeida e Giordan (2014). Cabe ressaltar que para transcrição do discurso, procuramos manter as características da oralidade como hesitações, pausas e marcadores conversacionais como "né?" e repetições do discurso (KODIC, 2008; MARCUSCHI, 2007), pois ponderamos que a supressão de alguns desses elementos poderia resultar em retextualização com mudança de significados (MARCUSCHI, 2007). Sendo assim, adotamos (/) para indicar uma pequena pausa, (//) para indicar que uma fala foi interrompida pela fala seguinte e duplo parêntesis (( )) para denotar alguns comentários contextuais.

Analisamos as transcrições por meio da comparação com as interações discursivas observadas em sala de aula com o discurso-fonte do TLDC. Para isso, comparamos o excerto do TLDC abordado na SD com as intervenções discursivas realizadas por professor e alunos em diferentes momentos da leitura. 
Para comparar o excerto do TLDC com as interações discursivas sobre o texto abordadas em sala de aula, analisamos o processo de retextualização por meio das operações de retextualização propostas por Marcuschi (2007), eliminação, acréscimo, substituição; e reordenação tópica; e as propostas por Silva (2013), condensação, construção de opinião própria e retomada; as quais foram utilizadas por Queiroz, Cabral e Silva (2017) para analisar processos de retextualização empregados na exposição oral de graduandos em Química.

Além disso, dadas as especificidades do contexto de sala de aula, as interações discursivas foram analisadas por meio das categorias de abordagem comunicativa (interativa de autoridade, interativa dialógica, não interativa de autoridade e não interativa dialógica) e dos padrões de interação I-R-A (iniciação do professor, resposta do aluno e avaliação do professor) previstas na ferramenta analítica de Mortimer e Scott (2002).

\section{Resultados e discussão}

Analisamos o discurso de um professor e alunas para verificar como ocorreram operações de retextualização do discurso do TLDC A Tabela Periódica durante a leitura desse, tendo em vista o conceito de retextualização definido por Marcuschi (2007). Consideramos importante analisar a retextualização, uma vez que quando materiais de divulgação científica são incluídos no contexto escolar, cabe ao professor realizar movimentos discursivos de adequação do discurso de divulgação científica à nova esfera de circulação (CUNHA; GIORDAN, 2015). Cabe frisar que no recorte deste trabalho, analisamos somente as operações de retextualização do texto escrito para o falado.

Conforme descrevemos previamente, foram selecionados cinco capítulos do TLDC para que os alunos apresentassem seminários. Os capítulos intitulados: Ouro; Niquel; Ferro; Chumbo e Mercúrio. Dentre os seminários apresentados, neste trabalho escolhemos analisar episódios de ensino referentes somente ao capítulo Ferro, pois foram nos episódios referentes a esse capítulo que encontramos um maior número de operações de retextualização.

Esse seminário foi apresentado por um grupo de alunas que utilizaram slides como suporte à exposição oral. Durante a apresentação, elas permaneceram o tempo todo em frente à sala de aula e se revezavam para que enquanto uma das alunas realizasse a exposição oral, outra, também integrante do grupo, passasse os slides. Em alguns momentos, sem que a apresentação fosse interrompida, o professor solicitou que alguns alunos que estavam conversando paralelamente durante a apresentação silenciassem. Contudo, cabe destaque que as alunas não se limitaram à leitura do texto ou do slide. Durante a apresentação, observamos diversas operações de retextualização, as quais iremos analisar por meio dos quadros apresentados a seguir, que trazem a comparação do discurso-fonte com a retextualização realizada pelas alunas. 
Quadro 1 - Retextualização de trecho do capítulo Ferro

\begin{tabular}{|c|c|}
\hline Discurso-fonte & Retextualização \\
\hline 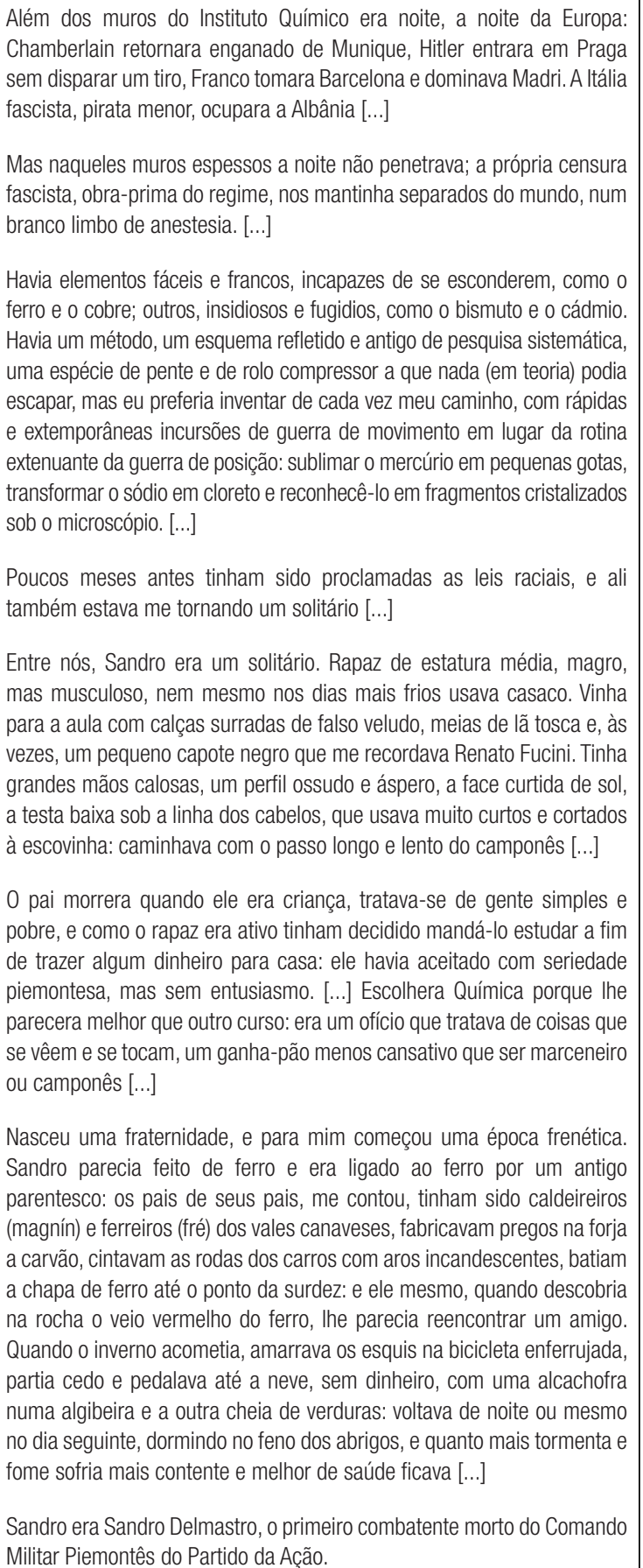 & 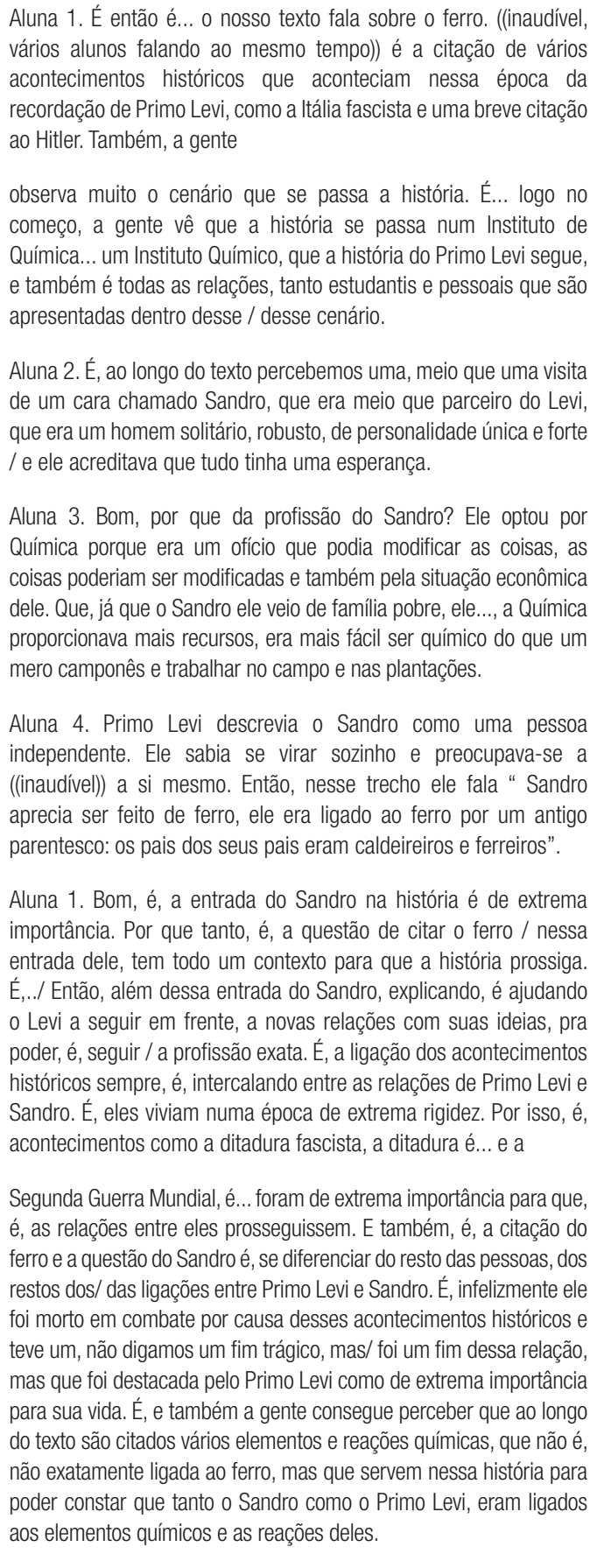 \\
\hline
\end{tabular}

Fonte: dados da pesquisa. 
No quadro 1, pode-se notar que cada aluna fez a retextualização de um parágrafo do capítulo. Cabe destacar que os parágrafos não são sequenciais, por isso no quadro colocamos os colchetes com reticências para indicar supressão de trechos não citados pelas alunas. Nesse caso, as alunas realizaram a operação de retextualização proposta por Marcuschi (2007) de reordenação tópica. Na retextualização realizada pelas alunas, nota-se que elas procuram manter fidelidade ao texto, pois o sentido apresentado não é modificado por elas, o que é esperado conforme os apontamentos de Marcuschi (2007) sobre retextualização. Por exemplo, a aluna 3 ao descrever as motivações para Sandro tornar-se químico enfatizou o aspecto econômico, o que também ocorre no TLDC. Contudo, cabe destaque que não são todas as informações apresentadas no discurso-fonte do TLDC que são apresentadas pelas alunas, ocorrem também operações de retextualização de eliminação e de condensação. Por exemplo, ao tratarem das características do personagem Sandro, a aluna 3 o descreve como um homem "solitário, robusto, de personalidade única e forte”. Não são mencionadas outras caraterísticas apresentadas no discurso-fonte, como estatura física e o tipo de vestimenta que utilizava. Nesse turno de fala também se nota a operação de retextualização acréscimo, pois a aluna 2 relata que o personagem Sandro era esperançoso, contudo, no texto não há menção a essa característica.

Também cabe destacar as ponderações da aluna 1 ao explicar o papel do personagem Sandro na história, bem como a relação das características com os acontecimentos narrados na história, por exemplo, quando ela menciona que a época vivenciada por eles era de extrema rigidez. Nesse caso, ocorrem as operações de retextualização de condensação e eliminação, pois no discurso-fonte são apresentadas descrições de algumas condutas fascistas, como a promulgação de leis raciais. Além disso, mesmo com as diversas menções no discurso-fonte aos conceitos químicos, nos trechos retextualizados o aspecto mais destacado pelas alunas é a amizade entre Sandro e Primo Levi, e não tanto conceitos químicos. Somente ao final, a aluna 1 menciona que tanto Sandro como Primo Levi estariam ligados aos elementos químicos. Nesses casos, também são constatadas as operações de retextualização condensação e eliminação.

Outro aspecto que também merece ser destacado é a organização dos textos dos slides, pois foram construídos retextualizando o capítulo do TLDC. Conforme Marcuschi (2007), a retextualização ocorre não somente do gênero textual para o oral, mas também de um gênero textual para outro gênero textual, de um gênero oral para outro gênero oral e de um gênero oral para um gênero textual.

Também com base na análise das informações apresentadas cabe destaque que as alunas iniciaram a exposição oral com uma abertura, na qual introduziram algumas considerações sobre o que apresentaram. Isso sugere que apresentam domínio sobre a estrutura de uma exposição oral acadêmica, uma vez que a abertura é parte da sua estrutura, conforme os apontamentos de Silva (2011). De acordo com a autora, a estrutura de uma exposição oral acadêmica é: abertura; desenvolvimento do assunto; conclusão e encerramento (SILVA, 2011). Nessa perspectiva, as falas das alunas 2, 3 e 4 referem-se à etapa de desenvolvimento do assunto da exposição oral acadêmica, pois explicitam informações apresentadas no texto.

Nesse sentido, cabe ressaltar que a última fala da aluna 1 se dá como continuidade à etapa da exposição oral de prosseguimento do assunto. Ao final, a aluna realiza a etapa de conclusão, quando declara que: 
E também a gente consegue perceber que ao longo do texto são citados vários elementos e reações químicas, que não é, não exatamente ligada ao ferro, mas que servem nessa história para constar que tanto o Sandro como o Primo Levi eram ligados aos elementos químicos e as reações deles. (Aluna 1).

Com base nas ponderações das alunas, o professor faz algumas considerações, também retextualizando o capítulo do livro. Nesse caso, notamos que o professor inicia a etapa de encerramento da exposição oral. 0 quadro 2, a seguir, traz uma comparação entre o discurso do professor e da aluna 1 e o discurso fonte do TLDC.

Quadro 2 - Retextualização de trechos dos capítulos Ferro e Níquel do TLDC A Tabela Periódica realizada pelo professor e pela aluna 1

\begin{tabular}{|c|c|}
\hline Discurso-fonte & Retextualização \\
\hline $\begin{array}{l}\text { Aqui, não: aqui a coisa ficava séria, o confronto com a Matéria. Mãe, } \\
\text { com a mãe inimiga, era mais duro e mais próximo. Às duas da tarde, } \\
\text { o Professor D., de ar ascético e distraído, distribuía a cada um de } \\
\text { nós um grama exato de certo pó muito fino: para o dia seguinte era } \\
\text { preciso completar a análise qualitativa, isto é, relatar que metais e } \\
\text { não-metais aí se continham. Relatar por escrito, na forma dissertativa, } \\
\text { de sim e de não, porque não se admitiam dúvidas nem hesitações: } \\
\text { de cada vez era uma escolha, uma deliberação; uma ação madura e } \\
\text { responsável, para a qual o fascismo não nos havia preparado, e que } \\
\text { exalava um bom odor, seco e limpo. [...] (Capítulo Ferro). } \\
\text { Entre nós, Sandro era um solitário. Rapaz de estatura média, } \\
\text { magro, mas musculoso, nem mesmo nos dias mais frios usava } \\
\text { casaco. Vinha para a aula com calças surradas de falso veludo, } \\
\text { meias de lã tosca e, às vezes, um pequeno capote negro que me } \\
\text { recordava Renato Fucini. [...] (Sandro parecia feito de ferro e era } \\
\text { ligado ao ferro por um antigo parentesco: os pais de seus pais, } \\
\text { me contou, tinham sido caldeireiros (magnín) e ferreiros (fré) dos } \\
\text { vales canaveses, fabricavam pregos na forja a carvão, cintavam } \\
\text { as rodas dos carros com aros incandescentes, batiam a chapa de } \\
\text { ferro até o ponto da surdez: e ele mesmo, quando descobria na } \\
\text { rocha o veio vermelho do ferro, Ihe parecia reencontrar um amigo. } \\
\text { [...] (Capítulo Ferro). } \\
\text { Tinha numa gaveta um diploma finamente ornado, no qual estava } \\
\text { escrito em caracteres elegantes que a Primo Levi, de raça judia se } \\
\text { conferia a licenciatura em Química com nota máxima e louvor: era, } \\
\text { pois, um documento ambíguo, uma metade glória, a outra escárnio, } \\
\text { uma metade absolvição, a outra condenação. Estava naquela } \\
\text { gaveta desde julho de 1941 e novembro havia terminado, o mundo } \\
\text { precipitava-se na catástrofe e em torno de mim não acontecia nada. } \\
\text { (Capitulo Niquel). }\end{array}$ & $\begin{array}{l}\text { Prof. É tem uma parte que daí vocês perceberam, tem uma ligação forte } \\
\text { dessa história aí, com a história que eles contaram do níquel, porque } \\
\text { quando eles, quando ele fala que ele entra pra faculdade, e aí tem um } \\
\text { professor que é super rígido, que tem que fazer a, separação, fazer análises } \\
\text { quantitativas, ele não aceitava menos do que, era excelência, né? Isso, } \\
\text { isso tudo construiu é / o conhecimento químico forte no Primo Levi que } \\
\text { posteriormente depois de formado, quando ele fala do diploma guardado } \\
\text { na gaveta desde 1941, e aí ele começou a utilizar os conhecimentos } \\
\text { químicos dele da faculdade, na/ na extração lá do níquel e outras coisas. } \\
\text { Aluna 1. Eaí também essa questão de o Sandro ser tão ((incompreensível)) } \\
\text { na natureza// } \\
\text { Prof. É, porque o Sandro no começo era uma pessoa muito tímida, não } \\
\text { parecia saber de nada, mas com o tempo ele passou a se demonstrar } \\
\text { como uma pessoa muito forte. / Então o ferro/ Então a gente vai, toda } \\
\text { essa história da tenacidade, da dureza, da dureza da vida do, do Sandro, } \\
\text { num contexto muito difícil, né, e ele faz a associação da vida do Sandro, } \\
\text { do passado do Sandro, pra tudo que ele que superar, ele até fala que ia } \\
\text { com calça que parecia de veludo, então, e que o Sandro gostava muito de } \\
\text { esportes, né? Gostava de esquiar, de fazer outras atividades// } \\
\text { Aluna 1. Ele descreve um pouco da vida do Sandro pra poder se // } \\
\text { Prof. É. Pensa que, com assim de admiração, né? Que ele, que ele teve } \\
\text { com/ com o Sandro e, por isso que o capítulo chama / ferro, né? Não o } \\
\text { elemento químico ferro, onde a maioria de vocês percebeu que o capítulo } \\
\text { apesar de trazer, os capítulos apesar de trazer elementos químicos ele } \\
\text { não fala sobre o elemento químico em si// } \\
\text { Aluna 1: Na verdade são associações, né// } \\
\text { Prof. É, e exatamente, ele usa os elementos químicos para descrever } \\
\text { situações, pessoas, fatos, do contexto da vida dele, que é uma reflexão } \\
\text { das propriedades dos elementos com o contexto que as pessoas estão } \\
\text { vivendo, no caso, aí da Segunda/ Guerra Mundial. }\end{array}$ \\
\hline
\end{tabular}

Fonte: dados da pesquisa.

Por meio da análise do quadro 2, pode-se observar que na retextualização realizada pelo professor são enfatizados aspectos da Química que não foram citados pelas alunas, as análises quantitativas realizadas. Nesse caso, notam-se as operações de retextualização 
de acréscimo, reordenação tópica, eliminação, condensação, substituição e retomada. A operação de retomada é observada em todos os turnos de fala, pois no processo de encerramento o professor e a aluna retomam diversos temas mencionados previamente. A operação de substituição é observada quando no discurso-fonte é utilizado o termo análises qualitativas, porém na fala do professor, ele substitui o termo por análises quantitativas. As operações de condensação e eliminação são evidenciadas nas menções do professor aos processos de análises químicas empregados, os quais no discurso retextualizado pelo professor são menos detalhados do que no discurso-fonte. Já a operação de reordenação tópica ocorre em todos os turnos de fala, uma vez que os interlocutores não se limitam a seguir a linearidade da narrativa apresentada no discurso-fonte, tanto que, na retextualização, relacionam informações presentes em outro texto, neste caso, do capítulo Níquel do TLDC, num processo de retextualização de acréscimo.

Também cabe destaque no quadro 2 para o fato de que as intervenções da aluna são feitas por meio da interrupção da fala do professor, e que, embora as falas dela também sejam interrompidas pelo professor, essas intervenções contribuem para a retextualização. Por exemplo, quando o professor afirma que os capítulos do TLDC não tratam do elemento químico em si e a aluna interrompe a fala dele e afırma que, na realidade, são associações. Nesse caso, nota-se a operação de retextualização de construção de opinião própria, o que sugere uma apreciação crítica do texto. Nesse cenário, consideramos que o fato da aluna interpretar de forma coerente as metáforas presentes no texto, relacionando-as com conhecimentos químicos ao explicitar as comparações presentes no TLDC referentes às propriedades dos elementos químicos com as características e condições de vida dos personagens, sugere indícios de letramento científico. Isso porque, de acordo com a perspectiva de letramento científico adotada por Santos (2007), sob a qual também nos guiamos, pode-se dizer que o letramento ocorre quando os estudantes incorporam conhecimentos científicos e os mobilizam em suas práticas sociais, sendo que, nesse caso, a prática social a que nos referimos é a apresentação oral realizada no contexto escolar.

Após a interrupção, o professor acata o comentário da aluna e encerra a sequência discursiva argumentando que os capítulos do TLDC trazem reflexões sobre as propriedades dos elementos químicos. Neste caso, consideramos que as reflexões indicadas pelo professor sobre as propriedades dos elementos químicos podem ser classificadas como uma das finalidades pedagógicas do uso de suportes de divulgação científica levantadas por Lima e Giordan (2013) de metacognição.

Além disso, nota-se que o professor faz uso da abordagem comunicativa interativa de autoridade para retextualizar o texto, o que sugere uma forma específica de adaptação do discurso de divulgação científica à esfera escolar, o que está de acordo com as ponderações de Almeida e Giordan (2014), que defendem que retextualizações de textos de divulgação científica tendem a reproduzir um discurso de autoridade, uma vez que a referência do discurso de divulgação científica é o discurso científico.

Entretanto, o professor não retextualiza somente trechos do capítulo Ferro do TLDC, ele também retextualiza trechos do capítulo Níquel com o intuito de indicar para os alunos as relações entre os textos. Nessa interação discursiva, observa-se uma aproximação com a inversão da tríade I-R-A, conforme observado por Candela (1999), pois nota-se, em certa 
medida, uma contravenção à autoridade do professor, uma vez que a aluna interrompe o professor e avalia implicitamente os comentários dele.

Após as retextualizações, o professor questiona as alunas acerca das dificuldades delas na leitura do texto, conforme pode-se observar na sequência discursiva apresentada na tabela 1 , a seguir.

Tabela 1 - Sequência discursiva 5 do episódio 9, das aulas 11-12 - Avaliação do capítulo Ferro

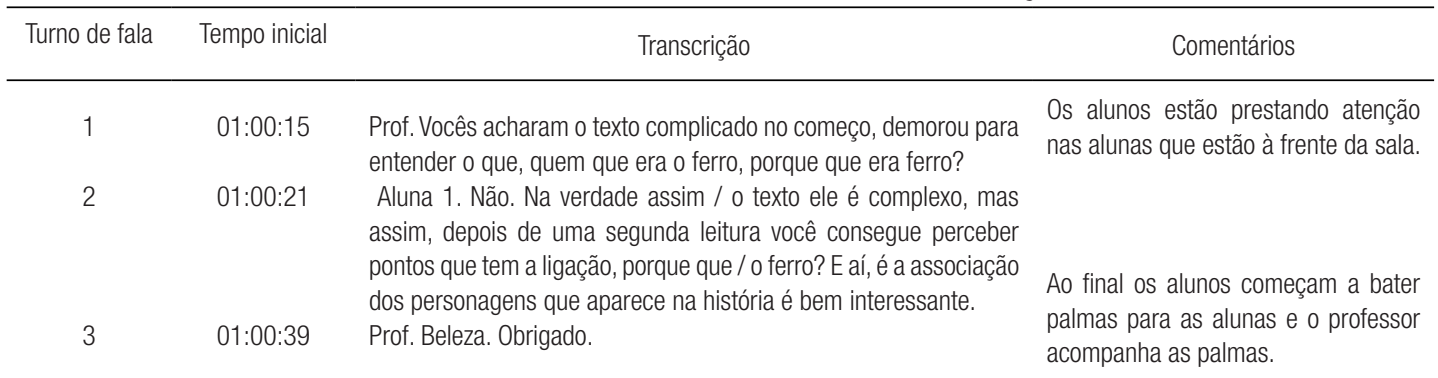

Fonte: dados da pesquisa.

Como se pode observar na sequência discursiva da tabela 1, a aluna não nega a complexidade do texto, porém o avalia como interessante pelo que ela denomina de “associações de personagens", realizando a operação de retextualização de construção de opinião própria. Pela qualidade das retextualizações realizadas pelas estudantes ao longo da exposição oral, nota-se um alto nível de compreensão do texto, conforme propõe a noção de horizontes de compreensão textual (figura 1) elaborada por Marcuschi (2008), que se refere às formas de leitura de um texto. Nota-se que elas fazem inferências e relacionam informações presentes no texto, o que se aproxima da perspectiva de leitura de horizonte máximo de compreensão textual, proposta por Marcuschi (2008). Além disso, não se notam nas falas delas extrapolações que contradizem o sentido do discurso-fonte. Contudo, esses resultados também sugerem algumas dificuldades de compreensão, pois nas retextualizações realizadas pelas alunas, no que se refere aos conceitos químicos, são observadas com maior frequência operações de retextualização de condensação e de eliminação.

\section{Considerações finais}

Em nossa análise, evidenciamos episódios que envolveram reflexões acerca de propriedades do elemento químico ferro, o que sugere uma potencialidade didática do TLDC. Para isso, as alunas e o professor realizaram processos de retextualização nos quais foram observadas as operações de retextualização propostas por Marcuschi (2007), eliminação, acréscimo, substituição; e reordenação tópica; e as propostas por Silva (2013), condensação, construção de opinião própria e retomada. Dentre as operações de retextualização, aquelas que ocorreram com maior frequência foram eliminação e condensação, o que sugere dificuldades de interpretação de alguns conceitos narrados no texto. Contudo, mesmo com as dificuldades observadas, consideramos que a diversidade 
de operações de retextualização encontradas, bem como a ocorrência da operação construção de opinião própria, são sugestivas das contribuições do TLDC para o processo de letramento científico das alunas.

Nas retextualizações observadas nas interações discursivas entre alunas e professor, foi feito uso de abordagem comunicativa do tipo interativa de autoridade e, em algumas interações, foi observada a tríade I-R-A, sendo que em uma das interações ocorreu algo próximo à inversão da tríade, em uma situação semelhante à descrita por Candela (1999). Consideramos que esses resultados são coerentes com os apontamentos de Cunha e Girodan (2015), que indicam que para a abordagem de suportes de divulgação científica em sala aula são necessárias adaptações, uma vez que o discurso de divulgação científica difere do discurso escolar. Nesse caso, acreditamos que a natureza das interações observadas é indicativa de adaptação do discurso de divulgação científica à esfera escolar. Além disso, esses resultados também estão coerentes com as indicações de Almeida e Giordan (2014) que defendem que retextualizações de textos de divulgação científica costumam reproduzir um discurso de autoridade, uma vez que a referência do discurso de divulgação científica é o discurso científico.

De modo geral, as operações de retextualização apresentadas sobre o capítulo Ferro sugerem potencialidades de trabalho deste TLDC em aulas de Química, uma vez que o texto propicia reflexões sobre propriedades de elementos químicos ao relacionar as propriedades do ferro com a personalidade de Sandro, o que foi percebido pelas alunas. Tais elementos podem ser considerados como uma das finalidades pedagógicas do uso de suportes de divulgação científica levantadas por Lima e Giordan (2013) de metacognição.

Tendo em vista esses resultados, consideramos que o texto pode servir de fonte para problematizar propriedades de elementos químicos e suas respectivas aplicações, bem como pode contribuir para ampliar o repertório cultural dos estudantes e desafiá-los a ler e interpretar gêneros textuais mais complexos e que não estão presentes no cotidiano deles, contribuindo assim para o processo de letramento científico dos estudantes.

Como um possivel desdobramento deste estudo, consideramos que em trabalhos futuros podem ser realizadas análises das produções escritas dos alunos relacionadas com os TLDC também abordando a noção de retextualização. É provável que essas análises possam fornecer ainda mais indícios acerca das potencialidades e limitações dos TLDC como ferramentas culturais abordadas em contextos de ensino.

\section{Referências}

ALMEIDA, Maria José Pereira Monteiro de; RINCON, Alan Esteves. Divulgação científica e texto literário: uma perspectiva cultural em aulas de física. Caderno Catarinense de Ensino de Física, Florianópolis, v. 10, n. 1, p. 7-13, 1993.

ALMEIDA, Sheila Alves de; GIORDAN, Marcelo. A revista Ciência Hoje das Crianças no letramento escolar: a retextualização de artigos de divulgação científica. Educação e Pesquisa, São Paulo, v. 40, n. 4 , p. 999-1014, 2014. 
CANDELA, Antonia. Student's power in classroom discourse. Linguist and Education, v. 10, n. 2, p. 139-163, 1999.

COELHO, Laura Lacerda; SALOMÃO, Simone Rocha. Ciência na literatura, literatura na ciência: caminhos para a leitura na formação de professores de biologia. Revista de Ensino de Biologia da Associação Brasileira de Ensino de Biologia, n. 7, p. 4644-4654, 2014.

CUNHA, Márcia Borin da; GIORDAN, Marcelo. A divulgação científica como um gênero de discurso: implicações na sala de aula. In: ENCONTRO NACIONAL DE PESQUISA EM ENSINO DE CIÊNCIAS, 7. 2009, Florianópolis. Atas... Rio de Janeiro: Associação Brasileira de Pesquisa em Educação em Ciências. Disponível em: http://axpfep1.if.usp.br/ profis/arquivos/viienpec/VII\%20ENPEC\%20-\%202009/www. foco.fae.ufmg.br/cd/pdfs/89.pdf. Acesso em: 20 out. 2020.

CUNHA, Márcia Borin da; GIORDAN, Marcelo. A divulgação científica na sala de aula: implicações de um gênero. In: GIORDAN, Marcelo; CUNHA, Márcia Borin da. (org.) Divulgação científica na sala de aula: perspectivas e possibilidades. ljuí: Unijuí, 2015. p. 67-85.

CUNHA, Márcia Borin da; GIORDAN, Marcelo. As percepções na teoria sociocultural de Vigotski: uma análise na escola. Alexandria: Revista de Educação em Ciência e Tecnologia, Florianópolis, v. 5, n. 1, p. 113-125, 2012.

GIORDAN, Marcelo. Computadores e linguagens na educação em ciências: uma perspectiva sociocultural para compreender a construção de significados. ljuí: Unijuí,, 2008.

GOUVÊA, Guaracira. A divulgação da ciência, da técnica e cidadania e a sala de aula. In: GIORDAN, Marcelo; CUNHA, Márcia Borin da (org.) Divulgação científica na sala de aula: perspectivas e possibilidades. ljuí: Unijuí, 2015. p. 13-41.

GRILLO, Sheila Vieira de Camargo. A noção de 'tema de gênero' na obra do Círculo de Bakhtin. Estudos Linguísticos, São Paulo, v. 1, n. 35, p. 1825-1834, 2006.

GROTO, Silvia Regina; MARTINS, André Ferrer Pinto. Monteiro Lobato em aulas de ciências: aproximando ciência e literatura na educação científica. Ciência \& Educação, Bauru, v. 21, n. 1, p. 219-238, 2015.

KODIC, Marília de Toledo. A caracterização do discurso oral por meio de marcadores conversacionais. Revista Anagrama, São Paulo, v. 3, n. 1, p. 1-8, 2008.

LIMA, Guilherme da Silva; GIORDAN, Marcelo. Propósitos da divulgação científica em sala de aula: estudos preliminares sobre sua presença no planejamento de ensino. In: ENCONTRO NACIONAL DE PESQUISA EM ENSINO DE CIÊNCIAS, 9., 2013, Águas de Lindóia. Atas... Rio de Janeiro: Associação Brasileira de Pesquisa em Educação em Ciências. Disponível em: http://www.nutes.ufrj.br/abrapec/ixenpec/atas/ resumos/R1164-1.pdf. Acesso em: 20 out. 2020.

MARCUSCHI, Luiz Antônio. Da fala para a escrita: atividades de retextualização. 7. ed. São Paulo: Cortez, 2007. MARCUSCHI, Luiz Antônio. Produção textual, análise de gêneros e compreensão. São Paulo: Parábola, 2008. 
MARTINS, Isabel. Dados como diálogo: construindo dados a partir de registros de observações de sala de aula. In: SANTOS, Flávia Maria Teixeira dos; GRECA, lleana María (org.). A pesquisa em ensino de ciências no Brasil e suas metodologias. ljuí: Unijuí, 2006. p. 297-321.

MORTIMER, Eduardo Fleury; SCOTT, Phil. Atividade nas salas de aula de ciências: uma ferramenta sociocultural para analisar e planejar o ensino. Investigações em Ensino de Ciências, Porto Alegre, v. 7, n. 3, p. 283-306, 2002.

PERISSÉ, Gabriel. Filosofia, ética e literatura: uma proposta pedagógica. 1. ed. Barueri: Manole, 2003.

PIASSI, Luís Paulo de Carvalho. De Émile Zola a José Saramargo: interfaces entre as ciências naturais e a literatura universal. Revista Brasileira de Pesquisa em Educação em Ciências, Belo Horizonte, v. 15, n. 1, p. 33-57, 2015.

QUEIROZ, Salete Linhares de; CABRAL, Patrícia Fernanda de Oliveira; SILVA, Erasmo Moisés dos Santos. Retextualização de artigos originais de pesquisa por graduandos em química. Enseñanza de las Ciencias, Barcelona, n. extra, p. 4647-4652, 2017.

SANTOS, Wildson Luíz Pereira dos. Educação científica na perspectiva do letramento como prática social: funções, princípios e desafios. Revista Brasileira de Educação, Rio de Janeiro, v. 12, n. 36, p. 474-550, 2007.

SILVA, Ana Virgínia Lima da. Com a palavra, 0 aluno: processos de retextualização na exposição oral acadêmica. 231 p. Tese (Doutorado em Estudos Linguísticos) - Universidade Federal de Minas Gerais, Belo Horizonte, 2013.

SILVA, Ana Virgínia Lima da. Operações de retextualização no gênero exposição oral acadêmica. Revista Memento, Três Corações, v. 2, n. 2, p. 70-89, 2011.

ZANETIC, João. Física e arte: uma ponte entre duas culturas. Pro-Posições, Campinas, v. 17, n. 1, p. 39-57, 2006.

Recebido em: 18.03.2019

Revisado em: 01.10.2019

Aprovado em: 25.11.2019

Arcenira Resende Lopes Targino é graduada em farmácia pela Universidade São Francisco (USF), licenciada em química pelo Instituto Federal de Educação, Ciência e Tecnologia de São Paulo (IFSP), mestra e doutoranda em educação pela Universidade de São Paulo (USP).

Marcelo Giordan é bacharel e mestre em química, doutor em ciências pela Universidade Estadual de Campinas (UNICAMP), livre docente em educação, é professor titular da Faculdade de Educação da Universidade de São Paulo (USP) e coordena o Laboratório de Pesquisa em Ensino de Química e Tecnologias Educativas (LAPEQ). 